\title{
RESUMOS DE DISSERTAÇÕES E TESES
}

Resumos impressos de acordo com os originais enviados pelas respectivas Coordenadorias de Pós-Graduação

\section{Instituto Nacional de Pesquisas da Amazônia}

\author{
TÍTULO: Maturação fisiológica de sementes de pupunha (Bactris gasipaes Kunth) \\ AUTOR: Sidney Alberto do Nascimento Ferreira \\ DATA: $\quad 04 /$ novembro/1996 \\ LOCAL: Instituto Nacional de Pesquisas da Amazônia, Coordenação de Pesquisas em Botânica, \\ Manaus-AM \\ NIVEL: Doutorado \\ BANCA EXAMINADORA: Isolde Dorothea Kossmann Ferraz - INPA (orientadora) \\ Rosane da Cunha - CENARGEM \\ Rubens Sader - UNESP \\ José Marcos Barbosa - IBt \\ Rita de Cássia Gonçalves Borges - UFV
}

\begin{abstract}
RESUMO - A qualidade da semente depende de inúmeros fatores dentre os quais destaca-se a época de colheita da mesma. A finalidade desta pesquisa foi identificar o periodo em que a germinação e o vigor das sementes de uma progenie de pupunha são máximos, bem como descrever as alterações visuais, fisicas e bioquimicas em frutos e sementes que ocorrem durante o processo de maturação. Foram avaliados também os efeitos do armazenamento das sementes nos frutos (tardios e precoces) com diferentes idades. As maiores taxas de germinação e vigor foram alcançadas aos 80 dias após a antese, quando se considerou que as sementes tinham atingido a maturidade fisiológica. A mudança de coloração de verde para amarela ou alaranjada na porção transversal maior dos frutos em pelo menos $50 \%$ dos frutos de um racimo, foi considerada um bom indice de maturidade da semente. Os atributos físicos dos frutos e sementes não puderam ser associados ao período de máxima emergência e vigor das sementes. Com o aumento da idade dos frutos, o número de dias para início da emergência diminuiu. À medida que aumentou a idade dos frutos o percentual de sementes com dormência também aumentou. Em frutos de maturação tardia, a dormência foi superada parcialmente, tanto mais quanto maior o periodo de permanência das sementes nos frutos.
\end{abstract}

Palavras-chave: Bactris gasipaes, semente, maturação

Agência financiadora: CAPES, INPA

TÍTULO: A familia Podostemaceae de alguns rios de água preta do Estado do Amazonas

AUTORA: Aldaléa Sprada Tavares

DATA: $23 /$ setembro/1997

LOCAL: Instituto Nacional de Pesquisas da Amazônia, Coordenação de Pesquisas em Botânica, Manaus-AM

NÍVEL: Doutorado

BANCA EXAMINADORA: Marlene Freitas da Silva - UTAM (orientadora)

William Antonio Rodrigues - UFPR

Jean-Louis Bernard Guillaumet - ORSTOM-FRANÇA

Olga Odinetz Collart - ORSTOM-UFPE

Marcus Gerardus Maria van Roosmalen - INPA

RESUMO - A família Podostemaceae conta atualmente com 48 gêneros e aproximadamente 271 espécies descritas, com distribuição quase exclusivamente intertropical, porém é para as Américas que encontram registrados o maior número de espécies. As Podostemaceae são muito 
polimórficas e bem adaptadas aos habitats de corredeiras e cachoeiras, com águas aeradas e transparentes. Seu aparelho vegetativo extremamente simplificado pode apresentar feições de algas, hepáticas ou liquens. Suas estruturas vegetativas refletem, muitas vezes, modificações como uma resposta adaptativa ao meio em que vivem. As espécies, anuais ou perenes, crescem submersas, fixas firmemente aos substratos e têm seu ciclo de desenvolvimento comandado pelas variações nos níveis das águas. Prováveis afinidades da familia Podostemaceae com outras familias têm sido inferidas porém, baseando-se em algumas características morfológicas observadas, aceitamos a colocação da família na Ordem Podostemales, na Sub-classe Rosideae. Foram realizadas observações sobre as variações morfológicas de algumas espécies, complementadas com observações ecológicas, para que pudessemos elucidar algumas questões sobre a delimitação de alguns táxons ocorrentes no Estado. Reconhecemos dezenove espécies e duas variedades, incluindo uma nova espécie, para o Estado do Amazonas, além de ter sido detectada a ocorrência de seis espécies novas para o Estado.

Palavras-chave: Podostemaceae, dicotiledônea, taxonomia, ecologia, reprodução Agência financiadora: $\mathrm{ORSTOM}, \mathrm{CNPq}$

TÍTULO: Caracterização agro-botânica de três cultivares de mandioca (Manihot esculenta Crantz) nos ecossistemas de várzea e terra firme no Amazonas
AUTOR:
José Jackson Bacelar Nunes Xavier
DATA:
06/março/1997
LOCAL: Instituto Nacional de Pesquisas da Amazônia, Coordenação de Pesquisas em Botânica, Manaus-AM
NÍVEL: Doutorado
BANCA EXAMINADORA: Luiz Antonio de Oliveira - INPA (orientador)
José Osmar Lorenzi - IAC
Tereza Louzada Valle - IAC
Ana Francisca Fernandes Corrêa - MCT
Newton Bueno - EMBRAPA

\begin{abstract}
RESUMO - Realizou-se esta pesquisa com os objetivos de determinar características botânicas e agronômicas de três cultivares de mandioca (Zolhudinha, Mãe Joana e Amazonas EMBRAPA-8), em várzea e terra firme; detectar descritores comuns aos ambientes para facilitar o reconhecimento dos materiais genéticos destinados aos trabalhos de melhoramento; e distinguir as fases de crescimento das três cultivares e suas relações entre os ambientes mencionados. Foram conduzidos dois experimentos, estabelecidos nas bases fisicas da EMBRAPA-CPAA, situadas em Iranduba (várzea) e Manaus (terra firme), municipios do Estado do Amazonas. Os tratamentos utilizados foram dois ambientes, três cultivares, oito épocas de colheita na várzea e onze na terra firme. O delineamento experimental foi de blocos ao acaso, com parcelas sub-divididas, para avaliar parâmetros botânicos, agronômicos e fisiológicos das três cultivares. Os resultados indicaram que os descritores qualitativos (cor, forma, ramificação da raiz, caule e peciolo) das três cultivares não sofreram influência dos ambientes estudados. A superioridade dos parâmetros botânicos, fisiológicos e agronômicos das cultivares, no ecossistema de várzea, foi marcante. A cultivar Amazonas EMBRAPA- 8 foi a mais eficiente na absorção de nutrientes e na produção de matéria seca, seguida pela Mãe Joana e Zolhudinha. Na várzea as cultivares absorvem os elementos quimicos em maior quantidade, de acordo com ordem decrescente: $\mathrm{N}>\mathrm{K}>\mathrm{Ca}>\mathrm{Mg}>\mathrm{P}>\mathrm{S}>\mathrm{Mn}>\mathrm{Zn}>\mathrm{Cu}>$ e em terra firme, a ordem de absorção foi $\mathrm{N}>\mathrm{K}>\mathrm{Ca}>\mathrm{P}>\mathrm{Mg}>\mathrm{S}>\mathrm{Mn}>\mathrm{Zn}>\mathrm{Cu}$. O ciclo máximo de desenvolvimento e crescimento variou de sete a oito meses em várzea e de nove a onze meses em terra firme. As épocas de maior acúmulo de matéria seca e o número de fases de crescimento da planta, foram menores do que os citados na literatura.
\end{abstract}

Palavras-chave: Manihot esculenta, caracterização agro-botânica, cultivares, ecossistema Agência financiadora: CAPES, CNPq, EMBRAPA 
TÍTULO: Influência do pulso de inundação na fisiologia, fenologia e produção de frutos de Hevea spruceana (Euphorbiaceae) e Eschweilera tenuifolia (Lecythidaceae) em área inundável de igapó da Amazônia Central

AUTORA: Lúcia Maria de Alencar Maia

DATA: $\quad 31 /$ julho/1997

LOCAL: Instituto Nacional de Pesquisas da Amazônia, Coordenação de Pesquisas em Botânica, Manaus-AM

NÍVEL: Doutorado

BANCA EXAMINADORA: Maria Teresa Fernandez Piedade - INPA (orientadora)

Wolfgang J.Junk - MAX-PLANCK

Maria Lúcia Absy - INPA

Edelcilio Marques Barbosa - INPA

Danielle Waldhoff-MAX-PLANCK

RESUMO - Este estudo foi realizado de julho de 1993 a dezembro de 1994, em área inundável de igapó, na região do baixo rio Tarumã-Mirim, com o objetivo de verificar a influência e a importância da dinâmica do pulso de inundação na fisiologia, fenologia e produção de frutos das espécies Eschweilera tenuifolia e Hevea spruceana. Observou-se o grau de adaptação e a resistência dos vegetais a períodos prolongados de cheia. A distribuição espacial das espécies ao longo do gradiente de inundação parece ser influenciada principalmente pela duração da cheia. H. spruceana e E. tenuifolia são indicadores de cotas baixas e também exigentes a altas taxas de luminosidade. $O$ padrão das curvas de saturação da fotossintese em função da radiação indica diferentes niveis de assimilação de $\mathrm{CO}$ relacionados à ontogenia da folha. A capacidade fotossintética média máxima em folhas maduras é $9^{2}, 0 \mathrm{mmol} \mathrm{m}^{-2} \mathrm{~s}^{-1}$ para $H$. spruceana e $8,8 \mathrm{mmol} \mathrm{m}^{-2} \mathrm{~s}^{-1}$ E. tenuifolia. As baixas concentrações de clorofila foram associadas ao processo de senescência e brotação. A anatomia foliar de $E$. tenuifolia mostra um grau de esclerofilia elevado, indicando que a espécie apresenta características consideradas adaptativas às condições de estresse hídrico, alta luminosidade e ventos. Já a anatomia da madeira parece assinalar uma diminuição da atividade cambial, relacionada ao ritmo periódico de abscisão das folhas. A estimativa da periodicidade do anel de crescimento e idade de árvores velhas de $H$. spruceana é dificultada pela presença de anéis periféricos reduzidos. Os frutos de $E$. tenuifolia $\mathrm{e} H$. spruceana são consumidos por espécies de peixes, entre estes a matrichã (Brycon sp.) e tambaqui (Colossoma macropomum).

Palavras-chave: Hevea spruceana, Eschweilera tenuifolia, pulso de inundação, fisiologia, fenologia, igapó Agência financiadora: INPA, MAX-PLANCK, SHIFT

TÍTULO: Caracterização morfológica, fertilidade e germinação do pólen do caiaué (Elaeis oleifera (Kunth) Cortés) -Arecaceae

AUTORA: Lúcia Helena Pinheiro Martins

DATA: $\quad 10 /$ janeiro/1997

LOCAL: Instituto Nacional de Pesquisas da Amazônia, Coordenação de Pesquisas em Botânica, Manaus-AM

NÍVEL: Mestrado

BANCA EXAMINADORA: Ires Paula de Andrade Miranda - INPA (orientadora)

Maria Lúcia Absy - INPA

Léa Maria Medeiros Carreira - MPEG

RESUMO - Foi realizado o estudo da morfologia polinica, fertilidade e germinação in vitro do pólen de dez populações amazônicas do Caiaué (Elaeis oleifera (Kunth) Cortés), visando contribuir para programas de melhoramento genético. As populações estudadas foram: Acajatuba, Amatari, Autazes, BR 174, Careiro, Manicoré, Maués, Moura, Novo Aripuanã e Tefé, introduzidas no banco de germoplasma da Estação Experimental do rio Urubu (EMBRAPA). A população Novo Aripuanã apresentou maior tamanho médio dos grãos de pólen e as populações BR 174, Moura e Amatari obtiveram as menores médias. Os grãos são elípticos ou piriformes de superfície micorreticulada e abertura monocolpada. Com relação à fertilidade, observou-se que o grão é binuclear, com núcleo vegetativo grande e alongado 
e o núcleo generativo compacto e arredondado, apresentando grãos potencialmente férteis. O pólen do Caiaué manteve uma viabilidade razoável durante o periodo experimental, chegando a seis meses de conservação à $-20^{\circ} \mathrm{C}$, com aproximadamente $100 \%$ de grãos germinados. Considerando a alta porcentagem de germinação após armazenamento, constatou-se que essa palmeira pode ser considerada promissora para o desenvolvimento de programas de melhoramento genético.

Palavras-chave: Elaeis oleifera, palmeiras, pólen, conservação

Agência financiadora: CNPq, INPA

TíTULO: Anatomia foliar de Aldina heterophylla Spruce ex Benth. (Leguminosae Papilionoideae): uma espécie das Campinas Amazônicas

AUTORA: Maria Gracimar Pacheco de Araújo

DATA: $\quad 09 /$ janeiro/1997

LOCAL: Instituto Nacional de Pesquisas da Amazônia, Coordenação de Pesquisas em Botânica, Manaus-AM

NIVEL: Mestrado

BANCA EXAMINADORA: Maria Sílvia de Mendonça - UA (orientadora)

Moacyr Euripedes Medri - UFLO

Germano Guarim Neto - UFMT

RESUMO - Aldina heterophylla Spruce ex Benth. Leguminosae, Papilionoideae é uma espécie facilmente encontrada em diferentes campinas da Amazônia Central. Possui caracteristicas morfológicas peculiares que revelam a sua interação com o ambiente, apresentando variação no seu porte nas diversas campinas, sob distintas condições de solo, luz e temperatura. O presente estudo foi realizado na intenção de conhecer o grau de escleromorfismo das folhas sob diferentes niveis de luminosidade e observar aspectos da plasticidade da espécie em relação às distintas condições ambientais. De foliolos coletados de dois microambientes (sol e sombra) dentro de três macroambientes (campina aberta, campina alta e campina sombreada), foram feitos cortes histológicos e dissociação de epidermes, para a descrição anatômica do foliolo e avaliação de alguns aspectos quantitativos do mesmo. De maneira geral, em todos os macroambientes a planta desenvolve estruturas escleromorfas podendo-se considerar a intensidade luminosa como um fator determinante do seu escleromorfismo. Consequentemente, as folhas de sol são relativamente mais escleromorfas que as de sombra. Os resultados sugerem que Aldina heterophylla está melhor adaptada às condições ambientais da campina alta, visto que ali apresenta crescimento exuberante, em relação à campina aberta e à campina sombreada.

Palavras-chave: Aldina heterophylla, anatomia foliar, anatomia ecológica, campina Agência financiadora: $\mathrm{CNPq}, \mathrm{UA}$

TíTULO: Caracterização floristica e estrutural das pteridófitas em uma área de floresta do Campus da Universidade do Amazonas-Manaus (AM)

AUTOR: Manuel Flores Arévalo

DATA: $\quad 09 /$ janeiro/1997

LOCAL: Instituto Nacional de Pesquisas da Amazônia, Coordenação de Pesquisas em Botânica, Manaus-AM

NIVEL: Mestrado

BANCA EXAMINADORA: Izonete de Jesus Araujo Aguiar - INPA (orientadora) Hanna Tuomisto - Univ. Turku/Finlândia

Jefferson Prado - IBt

RESUMO - Este trabalho tem como objetivos determinar as espécies de pteridófitas e verificar sua distribuição ao longo de três parcelas que foram instaladas entre uma vegetação de campinarana e vários gradientes topográficos denominados Baixio, Encosta e Platô na Reserva Biológica do Campus da Universidade do Amazonas, Manaus (AM). O método de amostragem empregado foi o sistemático linear. A área de estudo foi de 22 hectares. Os táxons de pteridófitas são 12 famílias, 17 gêneros, 24 espécies e 
quatro variedades. A maioria das espécies $(60 \%)$ foi encontrada em baixio. Analisou-se a distribuição das espécies ao longo das parcelas, verificando-se as suas preferências aos tipos de solos e habitats. Estudou-se também a similaridade da pteridoflora entre as diferentes posições topográficas da área de estudo. Foram efetuadas comparações com a ocorrência de pteridófitas em uma área de 0,5 hectare onde constatou-se que 10 espécies foram comuns em ambas as reservas. Em torno de $68 \%$ das espécies do Campus são terrestres, $24 \%$ são epifitas, $8 \%$ tiveram ambas preferências. O menor número de espécies encontrado no Campus comparado com o da Reserva Ducke sugere perturbações antrópicas nessas florestas. Com as pteridófitas do Campus elaborou-se uma chave geral de familias, gêneros, espécies e variedades que fornecerá subsidios a futuros taxônomos deste grupo de plantas.

Palavras-chave: Pteridófita, Amazônia, composição floristica, similaridade Agência Financiadora: CNPq, INPA, UA

TíTULO: Estabelecimento de plântulas de Copaifera multijuga Hayne (Caesalpiniaceae) em fragmentos florestais e estádios de sucessão

AUTORA: Maria Elisabeth de Assis Elias

DATA: 11/abril/1997

LOCAL: Instituto Nacional de Pesquisas da Amazônia; Coordenação de Pesquisas em Botânica, Manaus-AM

NÍVEL: Mestrado

BANCA EXAMINADORA: Isolde Dorothea Kossmann Ferraz - INPA (orientadora)

Rita de Cassia Mesquita - SMITHSONIAN-INPA

Gil Vieira - INPA

RESUMO - Neste bioensaio foi comparado o estabelecimento de plântulas de Copaifera multijuga Hayne em função de diferentes niveis de perturbação florestal, com as igualmente transplantadas na floresta primária. C. multijuga mostrou maior sobrevivência (80-95\%) na floresta primária e nos fragmentos florestais de 100 e 10 hectares. Nestas condições sombreadas as plântulas são suprimidas sem ou com pouco crescimento. A menor sobrevivência foi observada na pastagem, porém neste habitat, as plântulas apresentaram maior biomassa seca final $(4,0 \mathrm{~g})$, sendo que a floresta secundária foi o ambiente com melhor performance: alta sobrevivência $(80 \%)$ e bom crescimento $(1,9 \mathrm{~g})$. Os resultados mostraram que a espécie C. multijuga na sua fase inicial é tolerante ao sombreamento, podendo sobreviver durante muito tempo em estado suprimido, porém necessita de luminosidade para o seu desenvolvimento.

Palavras-chave: Copaifera multijuga, sucessão florestal, fragmentos florestais, plântulas, estabelecimento

Agência financiadora: CAPES, SMITHSONIAN

\section{Museu Nacional - UFRJ}

TíTULO: As espécies brasileiras do gênero Trigonia Aubl. (Trigoniaceae) na região sudeste

AUTOR: João Rodrigues Miguel

DATA: $\quad 10 /$ janeiro/1996

LOCAL: Universidade Federal do Rio de Janeiro, Museu Nacional, Departamento de Botânica, Rio de Janeiro, RJ

NÍVEL: Mestrado

BANCA EXAMINADORA: Jorge Fontella Pereira - JBRJ (orientador)

Luiz Emygdio de Mello Filho - UFRJ

Graziela Maciel Barroso - JBRJ

Jorge Pedro Carauta - FEEMA 